ISSN 1518-3483

Licenciado sob uma Licença Creative Commons

\title{
Engajando estudantes por meio da redação de bons casos: formação docente
}

\author{
Engaging students by writing good teaching cases: \\ teacher training
}

\section{Comprometiendo estudiantes por medio de la redacción de casos: formación docente}

\section{Aline Cadena von Bahten, Carlos Alberto Engelhorn*}

\section{Resumo}

O uso de problemas de contexto real em sala de aula objetiva a aprendizagem efetiva, a motivação e o engajamento de estudantes. Observa-se que as discussões promovidas nesse ambiente não alcançam esses propósitos se o caso não é bem escrito. Apresenta-se um estudo de caso sobre as dificuldades de professores na criação de estudos de caso e de aprendizagem baseada em problemas (PBL) que promovam o engajamento de estudantes. Foram analisados 30 casos redigidos por professores após a primeira parte das oficinas de formação docente da PUCPR e suas reflexões e discussões nesse processo. Avaliou-se a influência de um instrumento de apoio na redação de bons casos. 0 principal problema encontrado foi a 
presença de informações além do necessário, o que pode levar os estudantes a solucionar problemas em sala de aula, mas sendo incapazes de aplicar isso na vida real.

Palavras-chave: Estudo de caso. Aprendizagem baseada em problemas. Formação docente. Engajamento de estudantes. Contexto real.

\section{Abstract}

The use of real-world context problems aims to motivate and engage students in effective learning settings. Some discussions that are promoted in the classroom do not reach these purposes if the case is not well written. We present a case study on the difficulties in creating case studies and problem-based learning (PBL) that promote student engagement. We have analyzed the reflections and the cases written by 30 instructors that had participated on teacher training workshops of PUCPR. We have evaluated the influence of an instrument to support good cases writing. The main problem encountered was the presence of information beyond necessary. This may cause students that are able to solve problems in the classroom, but that are unable to apply this learning in real life.

Keywords: Case study. Problem based learning. Teacher training. Students' engajement. Real-world context.

\section{Resumen}

El uso de problemas de contexto real en el aula objetiva el aprendizaje efectivo, la motivación y el compromiso de los estudiantes. Las discusiones promovidas en el aula no alcanzan estos propósitos si el caso no está bien escrito. Presentamos un estudio de caso sobre las dificultades en la creación de estudios de casos y el aprendizaje basado en problemas (PBL) que promueven la participación de los estudiantes. Hemos analizado las reflexiones y los casos escritos por 30 instructores que habian participado de formación docente de la PUCPR. Hemos evaluado la influencia de un instrumento para apoyar la escritura de buenos casos. El principal problema encontrado fue la presencia de información más allá 
de lo necesario que puede conducir a los estudiantes que son capaces de resolver problemas en el aula, pero que son incapaces de aplicar este aprendizaje en la vida real.

Palabras clave: Estudio de caso. Aprendizaje basado en problemas. Formacion docente. Estudiante comprometido. Contexto real.

\section{Introdução}

A "taxonomia da pedago-patologia" de Shulman (1999) descreve as três patologias que sucedem aprendizagens malsucedidas: amnésia (o estudante esquece a informação apresentada), fantasia (o estudante não sabe que compreendeu um assunto de forma errada) e inércia (o estudante não consegue aplicar o que aprendeu). Essas supostas doenças são relacionadas a professores que apresentam tópicos em excesso para seus alunos, que não verificam se seus estudantes desenvolveram algum erro de fixação no fim de suas aulas e que não criam atividades para aplicar conceitos teóricos. Será que o uso de contexto real em sala de aula, por meio de casos e problemas, seria a prevenção para elas?

No modelo de ensino baseado em aulas magistrais e palestras, o estudante é apresentado ao conhecimento de um especialista e, geralmente, os fatos são de interpretação única ou representam uma "verdade”. Já em situações de contexto real, como no método de estudo de caso ou da aprendizagem baseada em problemas (PBL), os aprendizes constroem o conhecimento com a ajuda de um especialista, analisando casos em que as informações são configuradas para não encaminhar a uma verdade única (ELLET, 2007). Se o papel do professor vai além de apresentar informações (HARDEN; CROSBY, 2000), provocar os estudantes para a necessidade de aprender é necessário (BIGGS, 1999).

O uso de problemas em educação, na década de 1980, não era considerado inovador, pois problemas já eram utilizados em sala de aula. Diferentemente da apresentação real, que é encontrada na vida, os 
problemas eram usados mediante exercícios, apenas após os estudantes serem expostos a conceitos. No entanto, o problema deve ser um estímulo para a aprendizagem ativa (BARROW; TAMBLYN, 1980), ou seja, incitar a busca por conhecimento, com foco na aprendizagem dos estudantes e não na forma como o professor ensina (BARRET; MOORE, 2011).

O uso de problemas de contexto real por professores objetiva a aprendizagem efetiva, a motivação e o engajamento de estudantes. Entretanto, observa-se que nem sempre as discussões promovidas em sala de aula alcançam esses propósitos. Assim, professores iniciantes e experientes em PBL procuram ajuda para melhorar o engajamento dos estudantes em suas atividades (BARRET; MOORE, 2011). Biggs (1999), nesse sentido, sugere que a motivação seria um produto da forma como o professor ensina e que a aprendizagem resulta de atividades que engajem estudantes nos contextos criados pelo professor. Portanto, a forma de aplicação e a qualidade do caso discutido influenciam o resultado de aprendizagem obtido.

Para que a aprendizagem seja efetiva e engajadora, as aplicações de aprendizagem devem envolver situações significativas e desafiadoras (WIGGINS; MCTIGHE, 2005). Os casos ou problemas apresentados devem ser controversos e possibilitar diferentes caminhos de resolução, pois simulam uma situação real (ANDERSEN; SCHIANO, 2014; ELLET, 2007; ENGEL, 1997). Na criação de tarefas cognitivamente complexas para engajar estudantes, utiliza-se o conteúdo em uma nova apresentação de contexto, levando os estudantes a solucionar problemas, tomar decisões e investigar conceitos e eventos (MARZANO, 2017). Para alcançar o interesse intelectual deles, essas situações devem provocar um momento de imersão que envolva seu conhecimento e perspicácia e permita a conexão pessoal com o contexto criado (WIGGINS; MCTIGHE, 2005).

O estudo de caso e o PBL são histórias. Assim, um educador deve ser um bom contador de histórias, pois boas histórias são capazes de engajar estudantes e esclarecer conceitos. Narrativas convincentes tornam conceitos abstratos relevantes (WIGGINS; MCTIGHE, 2005) e devem ser interessantes do ponto de vista intelectual e emocional, para provocar o 
engajamento dos participantes (VEGA, 2017). Ainda, um bom professor é aquele que auxilia a aprendizagem do estudante. A capacidade de produzir materiais de aprendizagem está entre seus papéis, de acordo com Harden e Crosby (2000), que defendem o treinamento e acompanhamento de docentes para que possam selecionar, adaptar ou produzir objetos de aprendizagem e atividades de suas disciplinas.

Entretanto, os docentes relatam dificuldades para criar casos e problemas desenvolvidos sob medida para seu público-alvo, que cumpram as intenções do processo de ensino e aprendizagem e motivem e engajem estudantes. Eles podem recorrer a casos prontos com copyright de centros desenvolvedores de casos de universidades estrangeiras - alguns desses a custos elevados - mas, na realidade brasileira, costumam criar seus casos. Diante disso, este estudo analisa as dificuldades de professores na criação de problemas e contextos reais, observadas durante oficinas de formação docente e consultorias pedagógicas.

\section{Quadro teórico}

A PBL é um processo investigativo de situações ou fenômenos complexos que foram redigidos intencionalmente para a aprendizagem dos estudantes. O problema é um convite para solucionar curiosidades, dúvidas, incertezas, de forma que o estudante seja envolvido para buscar respostas para seus próprios questionamentos, em lugar daqueles propostos no exercício de um livro ou pelo professor em sala de aula. Essas experiências são interdisciplinares, pois oportunizam as múltiplas perspectivas de uma situação problemática autêntica (BARELL, 2007; BARRET; MOORE, 2011; BARROW; TAMBLYN, 1980; ENGEL, 1997). O contexto provoca a integração da teoria à prática e leva o estudante a buscar conceitos e formas para solucionar problemas (BARRET; MOORE, 2011; BARROW; TAMBLYN, 1980; SAVERY, 2015).

Herreid (2007) define estudo de caso como uma história com uma mensagem educacional, enquanto, para Christensen e Carlile 
(2009), é uma forma multifacetada de examinar uma situação. A discussão de um estudo de caso coloca os estudantes frente a uma experiência relatada, oportunizando o desenvolvimento de julgamentos ou estratégias referentes à situação apresentada. O aprendiz é colocado em ação ao ser provocado a pensar o que faria se estivesse naquela circunstância (ANDERSEN; SCHIANO, 2014).

Ainda para Herreid (2007), um bom caso inclui as seguintes qualidades: conta uma história, foca assuntos importantes relacionados ao tempo presente (até cinco anos), cria empatia pelos personagens centrais, inclui falas e pensamentos dos personagens, é relevante ao leitor, tem utilidade pedagógica, é conflitante, provoca tomada de decisão, trata do que é mais comum e é curto o suficiente para manter a atenção do estudante. A autora sugere que, se o professor precisar utilizar um caso mais longo, talvez fosse melhor dividi-lo em etapas. Em outra obra, Herreid (2012a) relata que o estudo de caso interrompido (em etapas), por apresentar dados incompletos, provoca o levantamento de hipóteses, a busca de informações e o refinamento de hipóteses ao longo das etapas; portanto, desenvolve as habilidades de investigação.

Por sua vez, Vega (2017) utiliza casos para educação em situações envolvendo empresas e negócios. Para ela, o caso é uma história factual, baseada em situações reais documentadas. Essas histórias são escritas no tempo passado, envolvem uma tomada de decisão ou opinião sobre um julgamento e provocam a análise da situação. Ademais, os casos e personagens não podem ser ficcionais, pois estudantes de negócios devem analisar os resultados de uma história real, sem elementos que poderiam distrair os leitores. Coletam-se, assim, dados dos atores envolvidos, que revisam e assinam a autorização para o uso do caso final, após sugerir alterações cabíveis, com autorização do comitê de ética para essa pesquisa.

Ao redigir suas histórias, o professor pode utilizar os conceitos de backward design, ou seja, ele analisa os resultados de aprendizagem desejados (aquilo que gostaria que seus estudantes fossem capazes de fazer), a forma como pode colocar seus estudantes em ação 
para alcançar esses resultados (as atividades de aprendizagem criadas pelo professor) e a forma como irá acompanhar (avaliação, assessment) o sucesso do processo (WIGGINS; MCTIGHE, 2005). Ao relacionar objetivos, método e avaliação para a aprendizagem do estudante, utilizam-se conceitos do alinhamento construtivo. Nesse sentido, afirma Biggs (1999) que o PBL é um exemplo de alinhamento construtivo em sua estrutura fundamental, pois o resultado de aprendizagem refere-se à capacidade do estudante de solucionar o problema, o método utilizado envolve o problema criado e a avaliação do processo relaciona-se à estratégia utilizada pelo estudante para solucionar a questão proposta.

A discussão de casos envolve: problemas, decisões e julgamentos. Nas etapas de análise de um problema, citam-se: a identificação do problema, o diagnóstico da situação, a análise de causa e efeito, conceitos e padrões envolvidos e ações a serem tomadas. Na tomada de decisão, analisam-se opções, critérios, recomendações e ações. Já no julgamento, avaliam-se critérios, termos, julgamento final, qualificações e ações (ELLET, 2007). Tarefas cognitivamente complexas que incluem a solução de problemas engajam os estudantes na identificação de obstáculos e na busca por soluções, considerando seus possíveis resultados (MARZANO, 2017).

A dificuldade relatada por professores na criação de casos e problemas motivou este estudo, que culminou na redação de instrumentos de apoio para aqueles que desejam produzir seus próprios cenários em sala de aula.

\section{Metodologia}

Foi realizado um estudo de caso sobre a dificuldade de criar problemas e contextos reais, que faz parte de pesquisa submetida e aprovada no comitê de ética da Pontifícia Universidade Católica do Paraná (PUCPR) sob o parecer 65161317.0.0000.0020. Os sujeitos do estudo foram professores do ensino superior que participaram das 
oficinas de formação docente de estudo de caso e PBL, realizadas de março de 2015 a novembro de 2016, na PUCPR, pelo Centro de Ensino e Aprendizagem (CrEAre), bem como aqueles que solicitaram apoio dos conselheiros pedagógicos em 2016 e 2017. Foram selecionados apenas os professores que participaram integralmente das oficinas e redigiram cenários que foram discutidos com os demais docentes, totalizando 22 sujeitos.

A primeira versão dos casos e problemas redigidos pelos professores constituiu o objeto de análise deste estudo, bem como os questionamentos e dificuldades apresentados pelos docentes ao longo das oficinas e reuniões, que foram coletados por meio de diário. A maioria dos professores adaptou suas histórias após as discussões entre pares, construindo novos casos.

Ao longo deste estudo de caso, foi identificada a necessidade de um Instrumento de Apoio Para Redação de Bons Casos (IAPRBC), o qual seria criado e adaptado para as experiências observadas dos professores envolvidos nas oficinas. O instrumento, desenvolvido em fevereiro de 2017, utiliza como critérios: o título do contexto, a plausibilidade do contexto criado, o significado do contexto para o público-alvo, as características dos personagens envolvidos, o uso de diálogos ou descrições de pensamentos, a relação do contexto com o(s) resultado(s) de aprendizagem pretendido(s), a presença de ambiguidade apropriada e o formato do contexto.

Esse instrumento foi apresentado a 50 professores, no fim de março e começo de abril de 2017, em conjunto com explicações e atividades que envolviam contexto real. Esses professores analisaram o IAPRBC e fizeram questionamentos e sugestões para melhoria da qualidade da interpretação do instrumento. O instrumento adaptado foi utilizado em uma nova oficina, realizada em abril de 2017. Oito professores redigiram um PBL para a segunda etapa dessa oficina utilizando o IAPRBC. Essas histórias foram analisadas como objeto deste estudo, considerando o uso do instrumento de apoio que foi criado para a intervenção no processo de criação de problemas e casos. 
Denominaram-se grupo controle os 22 casos em que os professores criaram seus contextos reais sem utilizar o instrumento de apoio e grupo intervenção os oito casos em que os professores utilizaram o instrumento como apoio na criação de suas histórias. Os grupos foram comparados, segundo as seguintes variáveis qualitativas: título do contexto, formato do contexto, se o contexto havia se transformado em exercício, presença da "voz do professor" por meio de perguntas ou explicações, presença de ambiguidades, personagens e presença de diálogos ou pensamentos dos personagens. Para essa comparação, optou-se pela representação gráfica das variáveis qualitativas analisadas.

\section{Resultado}

Após a análise das histórias criadas pelos professores e dos relatos em oficinas e reuniões, identificaram-se as dificuldades mais comuns na redação de contextos reais dos 22 casos estudados na fase inicial deste estudo, chamados posteriormente de grupo controle.

Com relação ao título escolhido para o PBL ou caso, observou-se sua ausência em seis casos, bem como o direcionamento da tomada de decisão, da solução ou da pesquisa intencionada por meio do título em oito. O direcionamento foi observado pela relação entre o contexto do caso ou PBL apresentado e os resultados de aprendizagem esperados pelos professores. Portanto, dos 22 títulos, oito foram considerados bons títulos, que despertavam curiosidade no estudante e não direcionavam a atividade.

Quanto ao formato do caso ou PBL, identificou-se dificuldade na diferenciação e forma de aplicação em 14 professores no início da oficina. Essa dificuldade foi documentada nas situações em que o docente não conectava as diferentes partes da história do PBL por meio do levantamento de tópicos de aprendizagem ou quando apresentava um estudo de caso como se fosse um PBL. 
Ao longo das oficinas, verificou-se que a história escrita funcionava como pré-texto para as perguntas, ou seja, o caso ou PBL havia se tornado um exercício. Isso foi identificado em 12 das primeiras versões apresentadas, nas quais o caso ou PBL não seria capaz de encaminhar os resultados de aprendizagem pretendidos. Esse fato foi encontrado nos casos em que as perguntas objetivadas pelo professor não estavam diretamente relacionadas ao contexto real utilizado ou poderiam ser respondidas pelos estudantes sem a necessidade de análise do caso elaborado. Outra apresentação de exercício observada no estudo consistiu em perguntas que estavam relacionadas ao caso, mas que dependiam da apresentação de mais dados que não estavam no texto durante a discussão, para que os estudantes pudessem relacionar a pergunta ao problema ou caso.

Identificou-se a presença da "voz do professor" nas histórias de duas formas. Primeiramente, foram em perguntas dentro do cenário, feitas pelo narrador ou personagens que representavam os questionamentos que o professor indicou como necessários às discussões. Isso foi registrado em situações em que essas perguntas apresentaram-se de forma irreal, forçadas ao longo do texto ou ditas por algum dos atores envolvidos na história. Observou-se isso em sete casos. Já a segunda deu-se nos casos em que se verificou uma explicação apresentada de forma diferente do que aconteceria na realidade (um personagem relatando com exatidão dados que ele não poderia saber) ou informações que, na vida real, deveriam ser buscadas pelo profissional (no caso, pelo estudante) para alcançar o resultado de aprendizagem identificado pelo professor - por exemplo, se algum personagem apresentasse uma ação que direcionasse ou entregasse a solução, simplificando o caminho do estudante. Esses fatos foram observados em 14 contextos escritos pelos professores.

Foi analisada, também, a presença de ambiguidades. Ela foi relatada nos casos em que a forma de apresentação do texto faria com que o estudante avaliasse mais de um caminho ou considerasse outras opções. Isso foi identificado em nove histórias. 
Outro ponto importante analisado, dizia respeito aos personagens criados nos cenários. Observou-se que os atores envolvidos nas histórias receberam nomes e características que permitiam identificar seus perfis, em dez dos contextos apresentados. Desses, em sete, foram descritos pensamentos ou frases ditas por esses personagens.

Todos os 22 contextos apresentados em sua primeira versão eram de situações significativas para o público-alvo.

Por sua vez, o instrumento de apoio criado baseado nos resultados apresentados foi utilizado por oito professores. Esse grupo foi chamado intervenção, tendo-se identificado os seguintes aspectos: todos os PBLs apresentaram título que provocaria o interesse dos estudantes, sem direcionar a solução do problema e quanto ao formato, em quatro, não havia uma segunda parte descrita e, desses quatro, dois professores não utilizaram o instrumento de apoio e dois relataram que trouxeram suas dúvidas para redigir a segunda parte do $\mathrm{PBL}$ em sala de aula. Nenhum dos contextos descritos apresentou-se como exercício e apenas dois dos problemas apresentados não incluíam ambiguidades em seu contexto. Em três dos problemas, havia perguntas que os personagens faziam e direcionavam os resultados de aprendizagem e em cinco dos casos, observou-se a "voz do professor" no texto por meio de informações que encaminhavam o resultado de aprendizagem. Apenas um dos cenários apresentados não incluía personagens com características plausíveis ao contexto; dos sete PBLs com personagens, em três não houve descrição de falas ou pensamentos.

A comparação dos resultados dos dois grupos foi feita por meio da representação gráfica das variáveis qualitativas analisadas. Observa-se que houve aumento das frequências relativas das características desejáveis (Gráfico 1) no grupo intervenção. Já com relação às frequências relativas das características indesejáveis (Gráfico 2), identifica-se a redução na porcentagem de exercícios no grupo intervenção, além de pouca alteração nas frequências da "voz do professor" nos dois grupos. 
Gráfico 1 - Frequência relativa das características desejáveis em contexto real

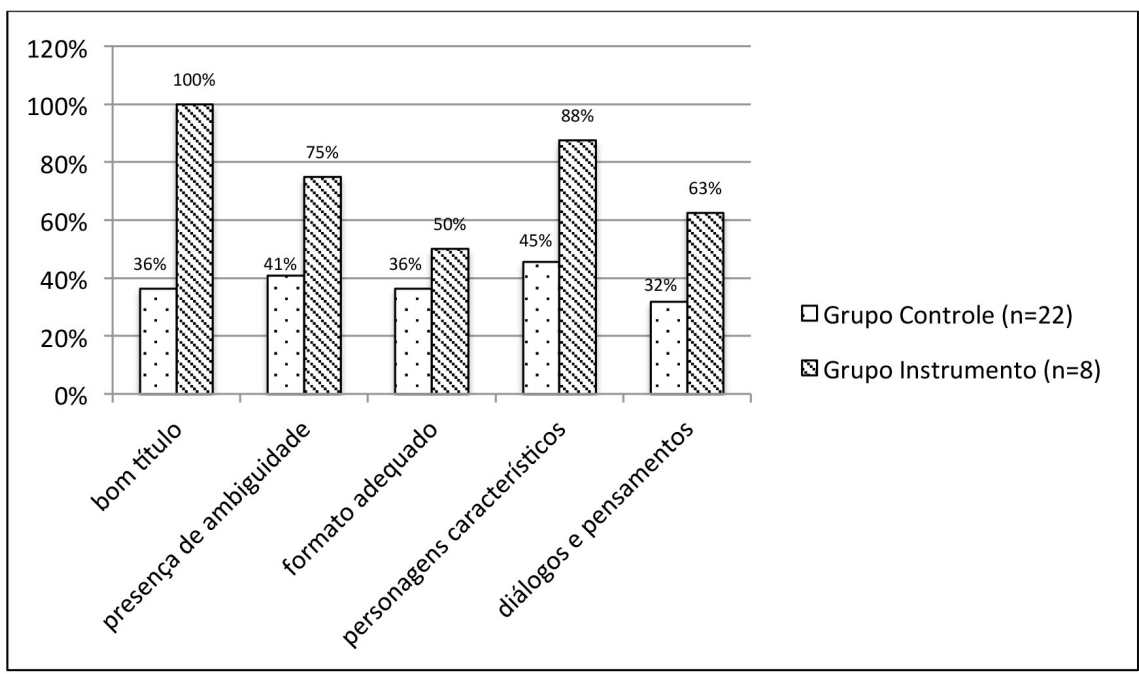

Fonte: Elaborado pelos autores (2017).

Gráfico 2 - Frequência relativa das características indesejáveis em contexto real

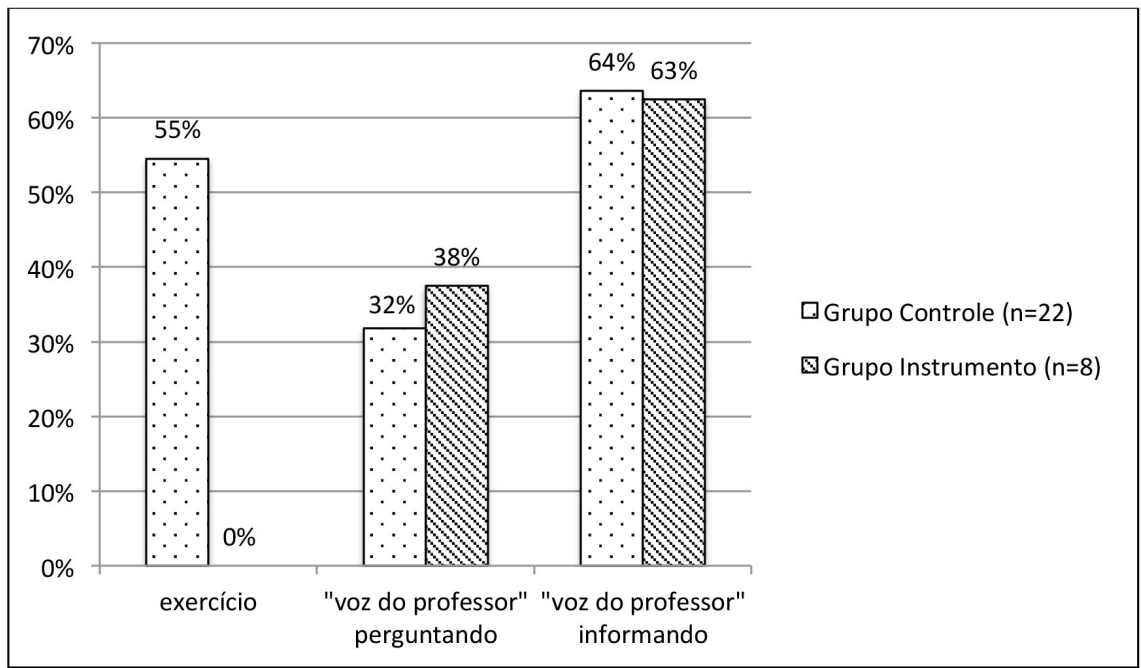

Fonte: Elaborado pelos autores (2017). 


\section{Discussão}

Este estudo de caso apresenta as dificuldades dos professores participantes na criação de casos e problemas que engajem seus estudantes e promovam o desenvolvimento dos resultados de aprendizagem pretendidos. Durante esta discussão, cada uma das situações será analisa em comparação com a literatura. Optou-se pelo método de estudo de caso devido ao pesquisador realizar uma análise qualitativa de um sistema delimitado (dificuldades na redação de casos e problemas objetivando o engajamento dos estudantes e a aprendizagem), relatando a descrição e temas do caso, com a intencionalidade de compreender o fenômeno e possibilidades de ação (CRESWELL, 2013).

Para que se atinjam os resultados de aprendizagem, o professor deve ser capaz de planejar experiências em que consiga acompanhar o estudante nesse intento (HARDEN; CROSBY, 2000). Se o problema do caso não é significativo ao público-alvo, ele não apresenta valor educacional. Em outras palavras, ele deve apresentar informações suficientes que permitam que os estudantes levantem conclusões sem definir apenas uma e discutam caminhos que possam ser embasados em argumentações (ANDERSEN; SCHIANO, 2014; CHRISTENSEN; CARLILE, 2009; ELLET, 2007; HERREID, 2007; WIGGINS; MCTIGHE, 2005).

Durante a redação do contexto real, o professor deve imaginar de que forma aquele caso ou problema será capaz de provocar as discussões e questionamentos planejados. Segundo Barell (2007), os problemas que provocam o engajamento são complexos, fascinantes, significativos, autênticos, intelectualmente desafiadores, levam à investigação ou tomada de decisão, permitem colaboração entre estudantes e são conclusivos (baseados em evidências e pesquisas). Estimulam-se, assim, a aprendizagem baseada em conhecimentos prévios, a reflexão sobre o contexto e a integração de conceitos e disciplinas (ENGEL, 1997).

Um bom caso conta uma história que é significativa para o público-alvo e cria empatia pelos personagens principais, por meio de atribuições de características que definem sua personalidade. As falas e 
pensamentos dos personagens auxiliam na formação dessa empatia, na compreensão e no engajamento dos estudantes (HERREID, 2007). Criar personagens interessantes que poderiam ser encontrados pelo futuro profissional na vida real não só engaja o estudante, como o provoca a pensar o que faria nessa situação. Esses fatores foram observados neste estudo, tendo o uso do instrumento de apoio facilitado a redação de casos e problemas que incluíssem esse aspecto.

O título deve provocar curiosidade, mas não deve direcionar a solução ou caminhos para ela; é, de fato, o primeiro convite ao leitor, devendo o professor ter isso em mente ao optar pelo título escolhido. Destacase que, na literatura, se encontram os mais variados nomes em bancos das universidades com essa apresentação (ELLET, 2007; HERREID, 2007, 2012a). Neste estudo, observou-se a presença de títulos que acabavam por indicar o problema ou caminho para sua solução. O uso do instrumento de apoio permitiu que, no segundo grupo, todos os professores escrevessem títulos que provocassem a curiosidade dos estudantes e não indicassem o assunto de que tratava a história.

De modo complementar, os estudantes devem passar por experiências que envolvam atividades e avaliações com ambiguidades, para desenvolver sua capacidade de interpretação (WIGGINS; MCTIGHE, 2005). A ambiguidade enriquece a discussão e provoca o estudante, mas deve ser colocada de forma realista, para que ele se preocupe em encontrar a solução do caso, pois atribuiu importância pessoal a essa história (HERREID, 2007; SAVERY, 2015). Um caso bem escrito apresenta algumas interferências, fatos irrelevantes ou conclusões descritas por personagens que podem ser considerados falsos, pois baseiam-se em pontos de vista ou interesses pessoais (ELLET, 2007). Essas provocações e ambiguidades são colocadas no texto pelo professor de forma intencional, para provocar discussões sobre assuntos específicos. Para alcançar isso, é interessante agregar informações que permitam que os estudantes coloquem em dúvida a palavra do personagem, sem entregar que o fato pode não ser real. Assim, em vez de o professor fazer uma pergunta direta sobre esse assunto, são os estudantes que, ao analisar a fala ou pensamento de um personagem, 
podem considerar os possíveis motivos para tanto e avaliar a veracidade da informação. Se, no mundo real, pessoas podem fazer afirmações irreais devido a emoções ou interesses, devem-se enriquecer os casos com esses fatos, para provocar o engajamento do estudante e a formação do senso crítico. Nesse sentido, foi observada a dificuldade no uso de ambiguidades durante o estudo, tendo o instrumento de apoio auxiliado o segundo grupo a criar histórias com dubiedades apropriadas para promover o senso crítico e a pesquisa.

Há autores, principalmente na área de negócios, que defendem que os casos devem ser escritos no tempo passado, baseados em fatos e advindos de pesquisas. Ainda, não se podem atribuir falas que não foram coletadas ou modificá-las, visto que consideram que personagens e diálogos criados podem distrair o foco do estudante (VEGA, 2017).

Herreid (2007) comenta as limitações impostas por regras na criação de estudos de caso e PBLs, afirmando que a maioria dos casos que utilizou e publicou ao longo dos anos poderia não ser classificada como tal nos moldes dessas regras. Também defende o potencial de entretenimento das histórias para auxiliar no processo de aprendizagem, engajamento e desenvolvimento do raciocínio crítico (HERREID, 2012b). Há, inclusive, casos baseados no fantástico, como o publicado pela professora Kathy Gallucci (2012) para a disciplina Introdução à Biologia, intitulado "O dragão em minha garagem”, que discute a validade de hipóteses científicas e formas para testá-las.

Um caso ou problema baseado estritamente em uma situação real apresenta as limitações do que foi relatado, selecionando-se aquele que atende ao resultado de aprendizagem pretendido. Para que se possam alcançar mais resultados de aprendizagem, a adaptação ou criação de casos é mais indicada. Assim, cria-se o caso para quaisquer resultados de aprendizagem desejados, em qualquer situação possível. Podem-se acrescentar fatos que provoquem uma discussão ética dentro daquela situação, para desenvolver o saber-ser, ou incluir ou modificar um dado para provocar uma ambiguidade desejada. 
Já a percepção da "voz do professor" nos textos de casos e problemas por meio de trechos informativos, levantada tanto nas oficinas quanto durante as consultorias pedagógicas, pode ser inferida como uma necessidade de o professor informar o estudante, assim como faria em uma aula teórica tradicional. É como se o professor quisesse ajudar o estudante naquele momento, enquanto escreve o caso. Assim, apresentam-se informações para que os casos ou problemas sejam semelhantes às situações reais descritas em livros. Entretanto, quando há excesso de informações, o aprendiz pode não reter essa aprendizagem.

O conceito de que cobrir conteúdos em sala de aula por meio da apresentação de conceitos resulta em aprendizagem é chamado por Wiggins e McTighe (2005) de expert blind spot, ou seja, o ponto cego do especialista. Ao fazer isso durante um estudo de caso ou PBL, o efeito pode ser o mesmo identificado em estudo realizado há 40 anos, em que se mostrou que estudantes do primeiro ano de medicina não se lembravam dos novos termos ensinados na anatomia (SHULMAN, 1999).

A aquisição de informação pura não provoca mudanças na forma como o estudante relaciona-se com o mundo. Essa mudança ocorre quando o professor estrutura os dados para que o estudante analise seu papel e avalie possíveis ações (BIGGS, 1999). Por isso, sugere-se que a apresentação de conceitos seja feita de forma indireta e, se possível, provocando o questionamento dos estudantes e levantamento de hipóteses ao longo das discussões ou ainda, se for a intenção, a pesquisa adicional. Ao acrescentar esses fatos geradores de confusão nos contextos utilizados em sala, o professor auxilia no desenvolvimento da visão sistêmica e do senso crítico de seus estudantes. Herreid (2012a), a esse respeito, relata que, na ciência, se trabalha com dados incompletos e pesquisa; portanto, os casos devem exigir flexibilidade e a habilidade de pensar em abordagens alternativas.

Outro problema relacionado a essa "voz do professor" nas histórias é que ela faz com que os estudantes identifiquem e solucionem o problema estabelecido. Assim, professor e aprendizes saem da sala de aula satisfeitos, com a falsa impressão de que, frente a um cenário semelhante 
em ambiente real, o estudante seria capaz de aplicar corretamente as estratégias utilizadas no contexto criado. Tomar uma decisão considerada correta não significa, necessariamente, que o estudante atingiu a compreensão sobre aquele assunto ou aprendizagem daquela conduta. Segundo Wiggins e McTighe (2005), a compreensão só é atingida quando o estudante faz a coisa certa e sabe explicar por que essa mesma conduta poderia ser apropriada em uma situação e talvez inadequada em outra. Portanto, saber excluir diagnósticos prováveis em situações de ambiguidade pode ser mais importante do que fazer o diagnóstico certo em cenários menos complexos.

A reflexão dos professores após as discussões levou-os a omitir informações ou acrescentar ambiguidades em suas histórias iniciais, para que colocassem seus estudantes em um cenário mais próximo do real. Essa dificuldade persistiu na primeira redação durante a oficina, mesmo no grupo que utilizou o instrumento de apoio. Talvez isso demonstre que, mesmo entre professores que desejam utilizar métodos que promovam a aprendizagem ativa, ainda é difícil perder os vícios como conferencista e acreditar que os estudantes serão capazes de encontrar o caminho para solução de problemas sem esse auxílio. Também durante as discussões em grupo, os professores conseguiram indicar mudanças nos casos dos colegas, mas referiram dificuldades para fazer o mesmo processo de forma individual. Dessa forma, pretende-se melhorar o instrumento, com orientações sobre como evitar a "voz do professor" em estudos de caso e PBLs.

O uso do recurso de explicar conceitos no corpo do texto do caso ou problema é possível quando não há a intenção de que o estudante encontre essas informações - por exemplo, quando saber aquele conceito não é o foco da aprendizagem, mas é necessário para sua análise, considerando o tempo em sala de aula e a maturidade do estudante. Assim, se o objetivo do problema é estudar o núcleo básico daquele curso por meio de um contexto real, pode ser necessário acrescentar algumas informações para reduzir a ansiedade do estudante e não desviar o foco do resultado de aprendizagem. Na medicina, seria um problema em que o objetivo é estudar anatomia/fisiologia no cenário de um paciente com alteração 
clínica específica. O desafio do problema não precisa ser o diagnóstico ou diagnóstico diferencial, mas relacionar e compreender os mecanismos envolvidos (BARROW; TAMBLYN, 1980; ENGEL, 1997).

O problema deve ser escrito da forma como o futuro profissional encontraria essa situação no cenário real e não de uma forma já organizada por outra pessoa que teve acesso à informação. Em outras palavras, as informações devem ser apresentadas de forma realística e relacionadas a resultados possíveis para as ações realizadas sequencialmente (BARROW; TAMBLYN, 1980), sendo a compreensão do estudante demostrada quando ele faz a transferência do que aprendeu a cenários novos e talvez mais complexos. Isso é fundamental, pois o tempo em sala de aula não permite que o professor recrie todas as situações existentes (WIGGINS; MCTIGHE, 2005). Assim, contextos significativos capazes de provocar a curiosidade, a investigação e o pensamento estratégico frente a situações reais podem ser mais efetivos em um desenho curricular que integre, organize e relacione as diferentes experiências a serem vividas pelos estudantes ao longo do curso.

\section{Considerações finais}

A redação de estudos de caso e PBLs que engajem estudantes e promovam aprendizagem é um desafio. Nesse sentido, compreender as dificuldades do professor nesse processo pode auxiliar no desenvolvimento de estratégias para a formação docente, tendo sido, neste estudo, o uso de um instrumento de apoio efetivo para melhorar a qualidade dos títulos, apresentar ambiguidades apropriadas, criar personagens característicos com falas e pensamentos para engajar os estudantes e evitar transformar seus contextos reais em exercícios. No entanto, ainda são necessários mais estudos para facilitar a formação de professores nesses contextos.

Este estudo de caso mostrou que as principais dificuldades dos professores estudados estavam em transformar seus casos em exercícios e evitar colocar informações além do necessário (voz do professor), 
correndo o risco de observar estudantes que solucionam problemas em sala de aula, mas não são capazes de aplicar isso na vida real. Assim, para evitar aprendizagens malsucedidas da "taxonomia da pedago-patologia" de Shulman (1999), a qualidade dos estudos de caso e problemas utilizados é fundamental.

\section{Agradecimentos}

Os autores agradecem o suporte financeiro do FINEP (Financiadora de Estudos e Projetos), as contribuições de Dilmeire Sant’Ana Vosgerau para este artigo, o auxílio de Cinthia Bittencourt Spricigo na construção de ideias para as oficinas de formação docente no uso de contexto real, e a revisão do instrumento de apoio por Rosane de Mello Santo Nicola.

\section{Referências}

ANDERSEN, E.; SCHIANO, B. Teaching with cases: a practical guide. Boston: Harvard Business School, 2014.

BARELL, J. Problem-based learning: an inquiry approach. Thousand Oaks: Corwin, 2007.

BARRET, T.; MOORE, S. New approaches to problem-based learning. New York: Routledge, 2011.

BARROW, H. S.; TAMBLYN, R. M. Problem-based learning: an approach to medical education. New York: Springer, 1980.

BIGGS, J. What the student does: teaching for enhanced learning. Higher Education Research \& Development, v. 18, n. 1, p. 57-75, 1999. Disponível em: <http://dx.doi.org/10.1080/0729436990180105>. Acesso em: 28 abr. 2017. 
CHRISTENSEN, C. M.; CARLILE, P. R. Course research: using the case method to build and teach management theory. Academy of Management Learning \& Education, v. 8, n. 2, p. 240-251, 2009. Disponível em: <http://www.jstor.org/ stable/40214593>. Acesso em: 1 maio 2017.

CRESWELL, J. Qualitative inquiry and research design: choosing among five approaches. 3. ed. New York: Sage, 2013.

ELLET, W. The case study handbook. Boston: Harvard Bussiness School, 2007.

ENGEL, C. H. Not just a method, but a way of learning. In: BOUD, D.; FELETTI, G. I. The challenge of problem-based learning. New York: Routledge, 1997.

GALLUCCI, K. Learning about the nature of Science with case studies. In: HERREID, C. F.; SCHILLER, N. A.; HERREID, K. F. Science stories: using case studies to teach critical thinking. Arlington: National Science Teachers Association, 2012.

HARDEN, R. M.; CROSBY, J. The good teacher is more than just a lecturer - the twelve roles of the teacher. Medical Teacher, v. 22, n. 4, p. 334-347, 2000. Disponível em: 〈http://www.tandfonline.com/doi/abs/10.1080/014215900409429〉.Acesso em: 1 maio 2017.

HERREID, C. F. What makes a good case? In: HERREID, C. F. Start with a story: the case method of teaching. Arlington: National Science Teachers Association, 2007.

HERREID, C. F. Can case studies be used to teach critical thinking? In: HERREID, C. F.; SCHILLER, N. A.; HERREID, K. F. Science stories: using case studies to teach critical thinking. Arlington: National Science Teachers Association, 2012a.

HERREID, C. F. Introduction. In: HERREID, C. F.; SCHILLER, N. A.; HERREID, K. F. Science stories: using case studies to teach critical thinking. Arlington: National Science Teachers Association, 2012b.

MARZANO, R. J. The new art of science and teaching. Bloomington: Solution Tree, 2017. 
SAVERY, J. R. Overview of problem-based learning: definitions and distinctions. In: WALKER, A. et al. Essential readings in problem-based learning: exploring and extending the legacy of Howard S. Barrows. West Lafayette: Purdue University, 2015.

SHULMAN, L. S. Taking learning seriously. Change: The Magazine of Higher Learning, v. 31, n. 4, p. 10-17, 1999. Disponível em: <http://dx.doi. org/10.1080/00091389909602695>. Acesso em: 1 maio 2017.

VEGA, G. The case writing workbook: a self-guided workshop. 2. ed. New York: Routleadge Taylor and Francis Group, 2017.

WIGGINS, G.; MCTIGHE, J. Understanding by design. 2. ed. Alexandria: Association for Supervision and Curriculum Development, 2005.

Recebido: 05/04/2017

Received: 04/05/2017

Aprovado: 26/05/2017

Approved: 05/26/2017 
